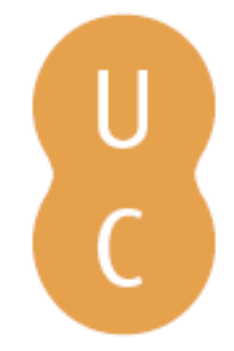

\title{
Rompalina
}

\section{Sinais de uma Cultura da Monumentalidade: as formas clássicas na arquitectura programática alentejana dos Sécs. XVI-XVII}

\author{
Autor(es): $\quad$ Patrocínio, Manuel F. S. do \\ Publicado por: Associação Portuguesa de Estudos Clássicos; Centro de Estudos \\ Clássicos e Humanísticos; Imprensa da Universidade de Coimbra \\ URL $\quad$ URI:http://hdl.handle.net/10316.2/31565 \\ DOI: $\quad$ DOI:http://dx.doi.org/10.14195/978-989-8281-69-2_21 \\ Accessed : $\quad$ 26-Apr-2023 16:00:12
}

A navegação consulta e descarregamento dos títulos inseridos nas Bibliotecas Digitais UC Digitalis, UC Pombalina e UC Impactum, pressupõem a aceitação plena e sem reservas dos Termos e Condições de Uso destas Bibliotecas Digitais, disponíveis em https://digitalis.uc.pt/pt-pt/termos.

Conforme exposto nos referidos Termos e Condições de Uso, o descarregamento de títulos de acesso restrito requer uma licença válida de autorização devendo o utilizador aceder ao(s) documento(s) a partir de um endereço de IP da instituição detentora da supramencionada licença.

Ao utilizador é apenas permitido o descarregamento para uso pessoal, pelo que o emprego do(s) título(s) descarregado(s) para outro fim, designadamente comercial, carece de autorização do respetivo autor ou editor da obra.

Na medida em que todas as obras da UC Digitalis se encontram protegidas pelo Código do Direito de Autor e Direitos Conexos e demais legislação aplicável, toda a cópia, parcial ou total, deste documento, nos casos em que é legalmente admitida, deverá conter ou fazer-se acompanhar por este aviso.

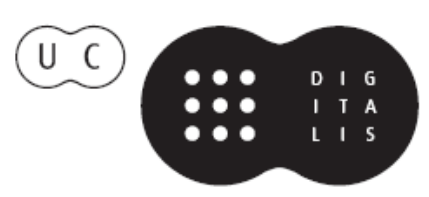




\section{Espaços e Paisagens}

Antiguidade Clássica

e Heranças Contemporâneas

Vol. III

Francisco Oliveira, Jorge Oliveira e Manuel Patrício

IMPRENSA DA UNIVERSIDADE DE COIMBRA 


\title{
SINAIS DE UMA CULTURA DA MONUMENTALIDADE: AS FORMAS CLÁSSICAS NA ARQUITECTURA PROGRAMÁTICA ALENTEJANA DOS SÉCS. XVI-XVII
}

\author{
Manuel F. S. Do Patrocínio \\ Universidade de Évora \\ Departamento de História
}

Centro de História da Arte e Investigação Artística

\begin{abstract}
All over the major constructive cycles that took place in Portuguese late $16^{\text {th }}$. and late $17^{\text {th }}$. Centuries, architectural treatises were the main obvious influence, giving origin both to the Mannerism and the so-called «Plain Style» local programmes and, later, at the birth of the $1^{\text {st }}$ Baroque in Portuguese arts. Vitruvian inspiration and, mostly, the lesson of Sebastiano Serlio brought to Portuguese creators the means to a new visual understatement which, nonetheless, conveyed the conceptual language of Classicism. The sense of order, ratio and reasoning was well suited to the constructive spirit of such times, having resulted in most distinctive works even in contexts of smaller scale, as in the case of accomplishments currently under survey as significant Heritage examples in the Évora territory, where they remain as signs of a longstanding tradition based on Classical formulae and aesthetics.
\end{abstract}

Keywords: Alentejo, architectural forms, architecture treatises, modern Classicism, Portuguese 'Plain-Style'.

Palavras-chave: Alentejo, Classicismo moderno, «Estilo-Chão», formas arquitectónicas, tratadística de arquitectura.

"Um edificio clássico é aquele cujos elementos decorativos derivam directa ou indirectamente do vocabulário arquitectónico do mundo antigo» ${ }^{I}$

O Classicismo formal e estético emerge da composição cultural e civilizacional que traz consigo a dignificação do indivíduo e da cidade, e que, sendo distintiva para o mundo grego, se reconhece no propósito de regra e harmonia essencial à convivência colectiva. A regra e a harmonia vieram também promulgar-se como essenciais à intenção construtiva. Neste âmbito, o classicismo arquitectónico tanto é pensamento, como linguagem que exprime esse pensamento através de elementos que são as formas construtivas ou decorativas. O modo prático como a arquitectura materializou tais pressupostos, tomou, entre os Romanos, a designação de ordem, aplicada

\footnotetext{
${ }^{1}$ J. Summerson 19943.
} 
à organização exterior com que se rematava a construção dos edifícios, na articulação proporcional do elemento coluna com o que lhe era superior: epistílio, arquitrave e friso, a cornija. Sendo a parte em que a edificação se oferecia à observação, o sistema de estrutura e super-estrutura identificará a ordem, no elemento formal que completa a obra ${ }^{2}$.

A lógica das formas e os sentidos subjacentes ao edificado constituem-se, como cerne da ideia construtiva, no âmbito do que se possa entender como uma apologia da monumentalidade, numa cultura em que a arquitectura é o objecto concreto de uma actividade, de reflexão e juízo. Nos sécs. XV-XVI, essa cultura toma uma forma escrita, ganhando estatuto de literatura. O precedente, ainda na Antiguidade, esteve na enumeração e descrição dos princípios a aplicar à arte da edificação (ou aedificatio) que coube ao protagonismo do Tratado de Vitrúvio, De architectura (séc. I), o primeiro texto a teorizar assumidamente a intervenção técnica e a propor um discurso conducente à monumentalidade, com os seus temas, num desígnio de perpetuar sentidos de memória. O discurso vitruviano comportava, de resto, uma notória marca historicista, à qual, conforme considerou Françoise Choay, se veio contrapor a concepção organicista que coube, a seguir, a Leon Battista Alberti (séc. XV), o primeiro tratadista moderno ${ }^{3}$.

Mas, ainda que com base numa justificação histórica em que se apela ao passado e à atenção ao exemplo, há um cunho de cientificidade e matematicidade em Vitrúvio, que, nomeadamente, recuperou a questão da teoria das proporções contida no anterior Cânone de Policleto (séc. V a.C.), e dirigida à arte da escultura, ou seja como técnica de aperfeiçoar a representação . Vitrúvio aplicará a proporcionalidade às relações das partes constitutivas dos edifícios, como instrumento de criação, enquanto individualiza, no âmbito das reflexões técnicas e teóricas, a objectividade da metodologia dos raciocínios de escala 4 .

O Tratado de Vitrúvio, consagrando a normatização técnica que era a súmula do Classicismo antigo e subordinando a intenção edificatória à apologia do Belo, concebe também o edifício como uma obra visual. Não havia estrutura que se pudesse desenhar que não fosse para suporte de determinados efeitos de imagem, nem imagem que se executasse, que pudesse subsistir sem tal suporte. Deste modo, as formas clássicas, resultado de ponderação, cálculo e técnica, adequavam-se não menos a sentidos estéticos, sendo um referente da interpretação da Natureza, como de significado histórico,

${ }^{2}$ Se «o património grego (...), foi o primeiro a superar uma posição étnica,», no seu «carácter de um modelo universal» (L. Benévolo e B. Albrecht 2003 200), a arquitectura clássica emerge, então, da síntese de soluções fixadas para «a arquitectura dos templos gregos e na arquitectura religiosa, militar e civil dos Romanos» (J. Summerson 1994 3).

${ }^{3}$ F. Choay 2007 133-143.

${ }^{4}$ Porque «a finalidade da proporção é estabelecer a harmonia de uma estrutura»(J. Summerson 1994 4), também as formas são elementos de valência aritmética. Portanto, «não é somente na forma das ordens em si que reside o carácter da arquitectura clássica. Na verdade, o seu carácter reside muito mais no modo como as ordens são desenvolvidas» (J. Summerson 1994 8-9). 
porque se assinalava, ao cabo das épocas, um auge no progresso humano, quanto à habilidade e domínio material. Também a emblemática dos motivos decorativos se reportaria a uma convergência com a memória, dadas as origens dos ornamentos, que teriam surgido em períodos arcaicos, persistindo nos costumes ${ }^{5}$.

No séc. XVI, Sebastiano Serlio (1475-1554) reactualiza a tratadística, oferecendo, na sua obra Regole generali d'architettura, formas e modelos visuais, que seriam, então, seguidos com o mesmo labor de ponderação que, na Antiguidade, se havia usado na programática edificada romana. A questão da concepção dos interiores é não menos importante, mas os edifícios que se fazem no séc. XVI são os que trazem já consigo a tradição europeia, formada na arquitectura cristã. As soluções de Serlio serão, sobretudo, de carácter formal. Cabe-lhe a canonização final do conjunto das ordens, que, em Vitrúvio, se consignavam ao dórico, jónico e coríntio, embora alargando-se também ao toscano, porém remetido a uma condição de uso arcaico e inscrito no cálculo do estabelecimento formal do dórico. Na obra de Serlio, o toscano, bem como o compósito, porque o primado é, agora, o do resultado da intenção de distinção das fachadas, são elevados à categoria de ordem, porque o objectivo torna-se, assim, o realce formal, conforme patente, de resto, noutro tratadista: Andrea Palladio (1508-1580), autor de I Quattri Libri dell'Architettura, de 1570 , de notável posteridade.

Mais que cópia ou retorno, ou mais do que mera ruptura com a «velha» edilícia, haverá antes uma síntese quanto à procura construtiva, que, em ciclos sucessivos, se liberta de uma antiga engenharia e acompanha o progresso do conhecimento científico, oferecendo um novo compêndio. O resumo serliano teve especial influência nos programas portugueses, sobretudo com o fomento subsequente ao reinado de D. João III (1527-1557) e, a partir de 1562, à regência de D. Henrique (futuro Cardeal-Rei), reflectindo-se em dois factos arquitectónicos como o novo Claustro do Convento de Cristo (Tomar) ou S. Vicente de Fora (Lisboa) ${ }^{6}$.

É pelo modo de aplicação das formas e no inequívoco propósito de monumentalidade que tais programas se assumem, em definição, como clássicos. A identificação das formas e elementos de ordem torna-se numa metodologia da observação da qualidade arquitectónica, fruto de recepção e

\footnotetext{
${ }^{5}$ «Ficarão surpresos com a quantidade de elementos curiosos que compõem o entablamento, todos com nomes próprios (...). Porquê mútulos, porquê tríglifos e métopas? Porquê gotas» (J. Summerson 1994 10). Seria a sobrevivência de ornamentos, ainda elaborados em madeira, que, em períodos primitivos, ornamentavam os templos, em funcionalidade ritual.

${ }_{6}$ Dada a influência de Serlio, «será pelo estabelecimento de séries morfológicas de capitéis, primeiro, e pelo reconhecimento dos sistemas de proporções utilizados (ou não) em função das ordens arquitectónicas, depois, que poderemos estabelecer com rigor científico estes importantes aspectos formais do nosso Renascimento» (J. E. Horta Correia 1991 34). Cf., também: J. E. Horta Correia 2002.
} 
transmissão de uma cultura erudita, ajudando a explicar o cerne estético de novos ciclos?

Na segunda metade do séc. XVI, também a cidade de Évora teve um surto arquitectónico importante de renovação construtiva, subdividida em dois momentos principais. No primeiro, entre 1540-1550, de fomento joanino, surgem realizações como a Igreja de $\mathrm{N}^{\mathrm{a}} \mathrm{Sr}^{\mathrm{a}}$ da Graça e a Capela do Bom Jesus de Valverde. No segundo momento, entre 1550-1570, edificou-se o Colégio do Espírito Santo, e seu complexo, e a Igreja de Santo Antão, evidenciando uma programática já tardo-quinhentista, que se acompanha em mais encomendas, com circunstância nas fundações monásticas e conventuais. Sente-se o papel pioneiro, tipológico e criativo de tais obras, de que derivam soluções técnicas e estéticas com caracterização duradoura da paisagem urbana eborense, como da paisagem monumental do território centro-alentejano. Denota-se, então, o início de clara diferenciação estilística, no meio-termo entre o Maneirismo e o vindouro «Estilo Chão», que prenuncia uma austeridade baseada no formalismo clássico.

A actual edificação da Igreja de Santo Antão comporta duas fases, subsequentes à demolição, circa 1550 , da primitiva capela medieval de Santo Agostinho e da Albergaria do Corpo de Deus (Ordem dos Templários). Na I fase (1557-1563), intervém o arquitecto Manuel Pires, que concebe o interior segundo o esquema de igreja-salão, de áreas intercomunicantes somente divididas com altas colunas. Um sismo de 1568 derruba a abóbada e, iniciandose a II fase (1570-1577), por falecimento do anterior mestre, intervêm Afonso Álvares e Brás Godinho, trazendo o aparato definitivo do templo ${ }^{8}$.

Destacam-se, a unir os três alçados da fachada, os pilares-contraforte de escala gigante e de ordem dórica, evidenciando uma concepção geométrica, em esquadria, formando módulos em que se inscreverão aberturas. Horizontalmente, definem-se igualmente três tramos, que projectam a divisão interior das naves e que estão, precisamente, divididos pelos pilares da fachada, a que se adiciona o reforço das esquinas em cunhal, nas quais, por sua vez, termina a própria Praça do Giraldo, área central do espaço urbano eborense. Em distinção, além do despojamento ornamental, a fachada não comporta, por exemplo, nichos, mas, ao invés, proporciona o rasgar de janelas em disposição

\footnotetext{
${ }^{7}$ O novo Claustro de Tomar será «o exemplo máximo da assimilação profunda dessa nova cultura reveladora das possibilidades da arquitectura portuguesa renascentista (...)», também «coeva de obras de idêntico sentido de pesquisa inovadora por parte de Andrea Palladio em Veneza», em «utilização exaustiva de uma aprofundada noção de espaço conjugada com um jogo hábil em que são utilizadas as ordens canonizadas, em composição de grande riqueza rítimica» (J. E. Horta Correia 1991 34).

${ }^{8}$ Brás Godinho era «oficial de pedraria muito competente (...), [que] levantou das ruínas todo o edifício (...), [e] teve de consolidar as colunas (...), rebocou internamente toda a obra, incluindo os fustes e fechou-se a nova cobertura» (T. Espanca 1966 247).
} 
equilibrada, repetindo a projecção vertical dos pilares, que, sendo estas janelas rectangulares, é salientada pelo respectivo recorte de moldura (fig. 1).

Ao nível da entrada, aparecendo o triplo portal, a monumentalidade adquire mais erudição, a partir da concepção com frontão triangular superior envolto num arco de volta perfeita, de simbólica triunfal, inserido no paramento e apoiando-se em pilastras que se desdobram junto aos elementos contrafortados. As portas laterais caracterizam-se pelo seu remate em duplo lintel, mais rebaixados, mas cumprindo papel essencial no equilíbrio visual, cuja dinâmica se encontra, não na projecção decorativa, mas na articulação acometida entre formas curvas, triangulares e rectas, acrescentando-se o efeito de desdobramento de forma, que surge como o duplo adintelado. Esta composição adquire, assim, o significado erudito que advém da aplicação das formas de acordo com a tratadística, sendo que em Serlio (Regoli, 1,1, 13) que encontraremos o esquema recuperado para o desenho de fachada de Santo Antão (fig. 2) ${ }^{9}$.

Salientando-se a iniciativa de uso destas formas, essenciais à identificação de um ciclo clássico eborense, Afonso Álvares teve igualmente responsabilidade na edificação da Igreja do Colégio do Espírito Santo, terminada em 1567, cabendo-lhe uma outra reconstrução significativa, também coeva: o Convento de Santa Helena do Monte Calvário. O Calvário, fundado em 1565, por instâncias da Infanta D. Maria de Portugal, seguia a regra monástica de $\mathrm{St}^{\mathrm{a}}$ Clara e S. Francisco, vindo o respectivo edifício ocupar o lugar de outra ermida medieval consagrada a Vera Cruz, cujo simbolismo se ligava à exaltação da figura de Santa Helena. Em 1569, os terrenos, sitos às Portas da Lagoa, que, a norte, se abriam na cerca amuralhada, começam a ser levantados, e, entre 1570-1578, Afonso Álvares encarregou-se do desenho. Sendo um convento feminino, não há entrada principal axial, e a respectiva monumentalização deste espaço revelou-se, então, na parede norte da igreja, que veio deter assim o papel de fachada, onde se repetiu a aplicação de pilares-contrafortados dóricos, na projecção dos tramos transversais do corpo da igreja, que se destacam com a sua base desenvolvida sobre plinto quadrangular (fig. 3).

Ao meio desta longa parede está a porta, pela qual se acedia para a igreja, também de emolduramento com lintel desdobrado. Tal emolduramento insere-se na estética formal toscana, que se fazia combinar com o dórico dos pilares, exprimindo-se assim o recurso às ordens arquitectónicas recuperadas da monumentalidade antiga, que sugeriam maior robustez e sobriedade, adequando-se à intenção austera de programas de função religiosa. A distinção

${ }^{9}$ «If a workman will make a Gate or a Door in a Temple or a Church, which is to be proportionated according to the place, then he must take the wideness within the Church, or else the breadth of the wall without. If the Church bee small, and have pilasters or pillars within it, then he may take the wideness between them, and let the same width in a four square, that is, as high as broad, in which four Square, the diagonal lines, and the other two cross cutting lines will not only thew you the wideness of the Dome, but also the places and points of the ornaments of the same Dome, as you see in this Figure» (Serlio, Regoli..., 1,1, 13; transcrição de Robert Peake, in Sebastiano Serlio 1982). 
entre toscano e dórico é sobretudo formal. Os pilares identificar-se-ão como dóricos devido à sua função estrutural, de suporte e apoio. Os emolduramentos identificam-se como toscanos, por aspectos que tanto se referem a efeitos de simplificação, como de desvio quanto às descrições vitruvianas que expunham a organização dos entablamentos, no que é, enfim, uma interpolação moderna. De facto, a origem para esta forma está no epistílio nos templos antigos, nas colunatas que suportavam uma dupla trave. A superior correspondia ao friso decorado com vários ornamentos (as placas de métopa, às vezes esculpidas, alternando com placas de tríglifo; gotas e mútulos, colocados na divisão entre trave e friso).

Em diferenciação, o toscano, mantendo a dupla trave, caracterizava-se pela ausência dos indicados ornamentos. Mas, emoldurando portais e janelas, transpõe, em imitação de forma, o efeito visual de réplica da super-estrutura dos antigos templos. Ou seja, não se tornava «útil» mas contribuía para o arranjo combinado de formas visuais, denotando o uso do decorativo do próprio elemento arquitectónico, sem que fosse necessária mais ornamentação que contrariasse o uso austero destas obras. O uso do duplo lintel, apoiado no modelo serliano, surge nas realizações de Afonso Álvares, mas prolonga-se, como forma essencial da própria arquitectura que se desenvolve a seguir (fig. 4 e 5).

O recurso manteve-se, exemplo da Igreja do Convento do Senhor Salvador do Mundo (Praça do Sertório), com tipologia de fachada que se sucede já em período filipino, composta de parede unificada, própria de espaço com nave única, em que se distinguem os cunhais reforçados de pilar, a porta monumentalizada com duplo lintel e frontão de empena, a definir um eixo vertical onde se inscreve um largo óculo redondo. O modelo repete-se no portal lateral (poente), de idênticas dimensões ao axial (fig. 6).

Reporta-se este Convento, e sua igreja, a outra comunidade instituída ainda em 1550, entretanto desalojada pela obra do Colégio do Espírito Santo, pois esse primeiro edifício ocupava os terrenos da Companhia de Jesus que foram aproveitados para o estabelecimento da Universidade. A Abadessa Catarina de Aguiar diligenciou, então, a aquisição do velho Palácio dos Condes de Sortelha, que viria a ser derrubado sobre inícios de séc. XVII. A clausura mudou-se em 1604, ano que marca o início da construção da citada Igreja e Convento, e cuja primeira missa se realizou em 1610. Conforme Túlio Espanca, esboçouse então a «alta empena de cunhais de granito emparelhado, ornamentados nos vértices por guarnição de tríglifos» e «discreto portal assente sobre três degraus, da mesma pedra, terminado por frontão triangular onde subsistem vestígios de composição pintada a fresco» ${ }^{10}$.

Os pilares exteriores da Igreja do Salvador mantêm, pois, em combinação com portais toscanos, os elementos de decoração dórica, tríglifos e gotas, na zona de remate do pilar, que, desprovido de capitel, conserva no entanto, sobre a sua gola e a saliência de equino, uma zona apta à função de friso; na

10 T. Espanca 1966231. 
verdade, a cornija da parede prolonga-se pelo pilar, em continuidade. Surge, neste desenho, o que se designa precisamente como ordem abreviada, método não menos decisivo para a caracterização arquitectónica deste período, pois corresponderá ao cerne técnico que, apoiado na tratadística, origina o «EstiloChão» português, e que surgia também aplicado na fachada da Igreja de Santo Antão ${ }^{11}$ (fig. 7).

Ciclos posteriores prolongarão tais soluções de depuramento formal, mantendo-se no próprio arranque do Barroco português, em realizações já da época de D. Pedro II e persistindo o uso de formas clássicas na tradição portuguesa. Um caso de interesse está na Vila de Mourão, que, embora sendo de fundação leonesa, parece ter sido reconstruída nos finais do séc. XVII, talvez indicando a importância que grupos sociais locais adquiriram na sequência da Restauração.

Com efeito, o Castelo foi o único vestígio construtivo medieval que se manteve na Vila, correspondendo os restantes exemplos a obras subsequentes a 1681, em que se confere, por Decreto régio, instrução para a reconstrução da Igreja Matriz, consagrada a $\mathrm{N}^{\mathrm{a}} \mathrm{Sr}^{\mathrm{a}}$ das Candeias, de que existira um anterior templo manuelino. Reedificada entre o alinhamento das muralhas, onde está em proeminência visual, destaca-se, na fachada, a respectiva esquadria, demarcada por pilares, gigantes, em xisto, cruzados com molduras horizontais que definem as linhas de alçado. Mas o Barroco anunciava-se no nártex reentrante, que, pela primeira vez, corta o sentido rígido das linhas de frontaria vigentes (fig. 8).

Foi engenheiro responsável D. Diogo Pardo Osório, arquitecto militar, que, no séc. XVII, esteve também envolvido nos projectos de arranjo dos sistemas defensivos alentejanos, de que resultou não só a edificação dos revelins e baluartes em torno da Muralha de Évora, como a própria cerca seiscentista de Mourão, sobranceira ao Castelo e que obrigara à demolição do núcleo adjacente, onde estava, de resto, a velha igreja. As ruas da Vila terão mantido um sentido linear, semi-radial quanto ao ponto de partida de que o Castelo é o centro, mas que, de qualquer forma, seria já o anterior. Porém, outras marcas subsistiram, nomeadamente, os nichos de altar dispostos por várias ruas, que servem o propósito das celebrações da Paixão. Certo é, tais altares, inicialmente sete, indicando as Estações dos Passos do Senhor, seguem ainda o modelo erudito serliano, clássico, com abertura encimada de frontão triangular $^{12}$ (fig. 9 e fig. 10).

Indissociáveis, pois, de uma paisagem cultural única, todos estes exemplos de uma arquitectura programática são, por definição, clássicos, e não apenas

\footnotetext{
${ }^{11}$ Ordem abreviada é aquela onde os elementos formais da arquitectura se compõem a partir da «economia de alguns dos seus elementos constituintes» (P. Varela Gomes 2002 187). Com efeito, «a cornija servirá de capitel, diz Serlio»; assim temos «uma ordem apilastrada dórica na qual parte do capitel aparece em ressalto sobre o entablamento. A cimalha e o ábaco do capitel desaparecem sob a cornija e o friso do entablamento» (P. Varela Gomes 2002 188).

${ }^{12}$ Dos cinco Passos subsistentes, o que está na Rua Machado Santos comporta o cronograma de 1698. Na Praça da República conserva-se igualmente, num friso de janela de duplo lintel
} 
porque decorrem de uma linguagem e um pensamento construtivo, com sintaxe formal de origem antiga. São clássicos pelo pensamento que lhes está subjacente quanto a valores de equilíbrio, proporcionalidade, harmonia e imponência monumental, ainda que adequando-se ao propósito austero, mas reatando o sinal visível de uso e organização das formas arquitectónicas que exprimiam uma cultura erudita, a qual era, assim, apanágio de encomendas promovidas pela iniciativa régia ou eclesiástica que se alargavam a uma geografia definida. 


\section{Anexos}

Fotografias de Manuel F. S. Patrocínio (Évora e Mourão) e Clara Duarte Oliveira (Évora)

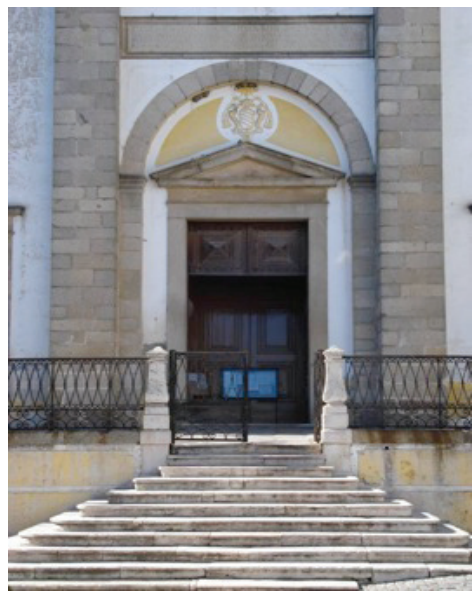

Fig.1 . Manuel Pires, Afonso Álvares e Brás Godinho. Igreja de Santo Antão. Évora (1577). Fachada axial. Acesso e portal central emoldurado entre arco redondo e pilares-contraforte centrais

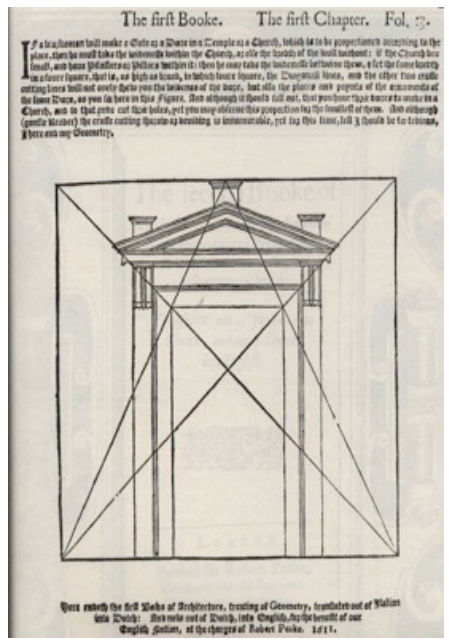

Fig.2. Sebastiano Serlio (1537). Modelo de portal dórico, in The Five Books of Architecture. Nova Iorque,

Ed. Robert Peake [1611] (1982, edição facsimile), 1,1, fl. 13 


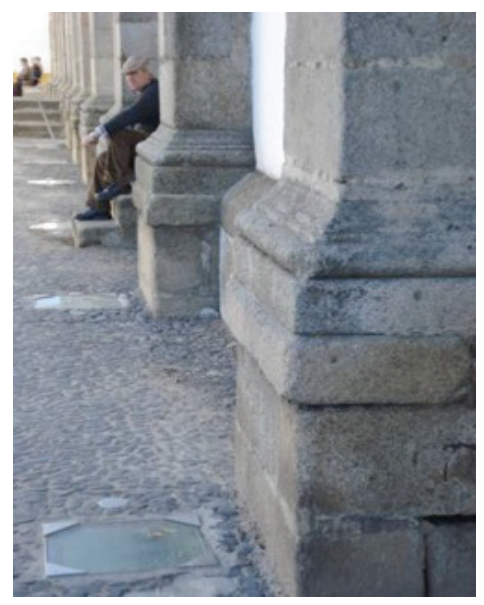

Fig.3. Afonso Álvares. Igreja do Convento de Santa Helena do Monte Calvário. Évora (1578). Fachada lateral. Detalhe dos embasamentos dos pilares-contraforte

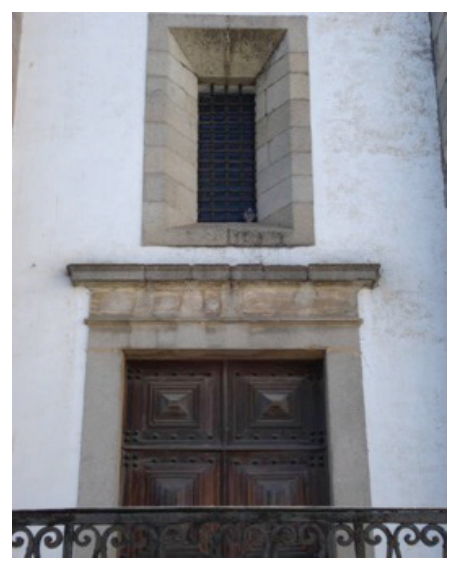

Fig.4. Igreja de Santo Antão. Évora (1577). Fachada. Detalhe do portal lateral nascente, com duplo adintelado, e abertura superior 


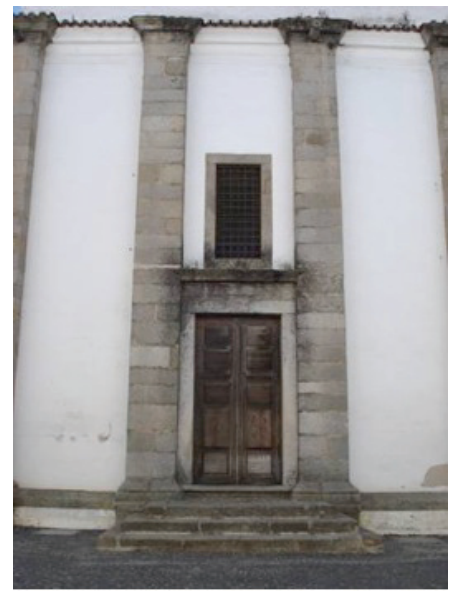

Fig.5. Igreja do Convento de Santa Helena do Monte Calvário. Évora (1578). Fachada lateral. Detalhe do portal central, com duplo adintelado, e articulação com abertura superior entre pilares-contraforte

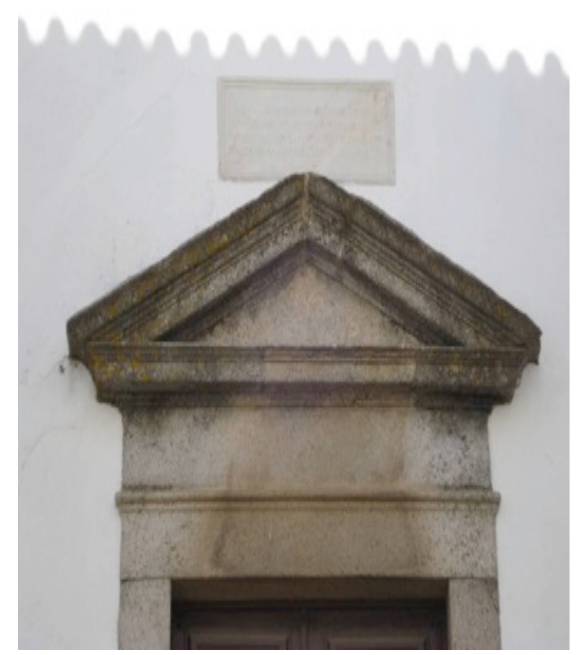

Fig.6. Igreja do Convento do Senhor Salvador do Mundo. Évora (1610). Fachada lateral poente. Detalhe do portal central, com duplo adintelado e frontão triangular com cornija e múltiplo ressalto 


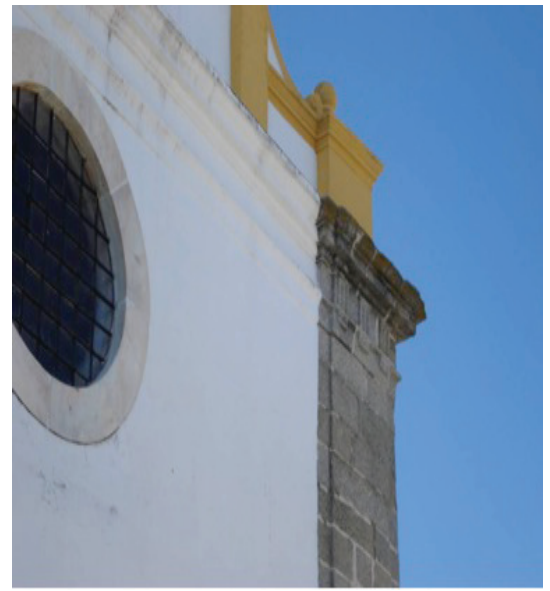

Fig.7. Igreja do Convento do Senhor Salvador do Mundo. Évora (1610). Fachada axial. Detalhe de óculo, friso contínuo liso e cornija de múltiplo ressalto e cunhal com elementos decorativos de tipologia dórica

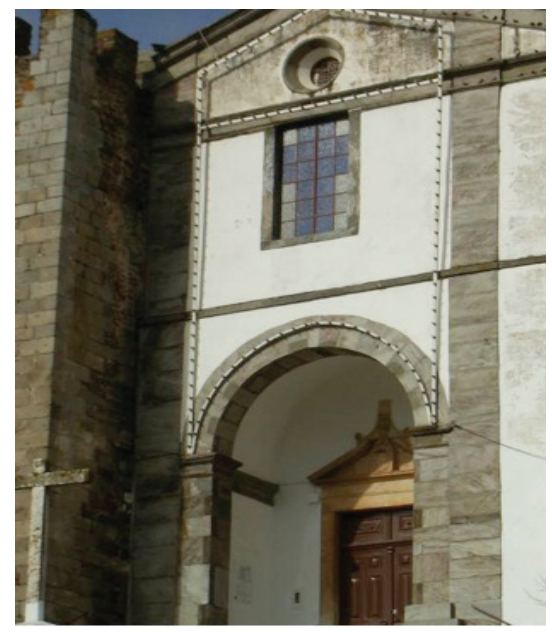

Fig.8. Diogo Pardo Osório. Igreja-Matriz de Nossa Senhora das Candeias. Mourão (ca. 1690). Fachada axial. Detalhe do portal central, entre pilares-contraforte inscritos e torreão da muralha medieval, com nártex reentrante sob arco redondo e em articulação com abertura superior e óculo no tímpano de frontão 


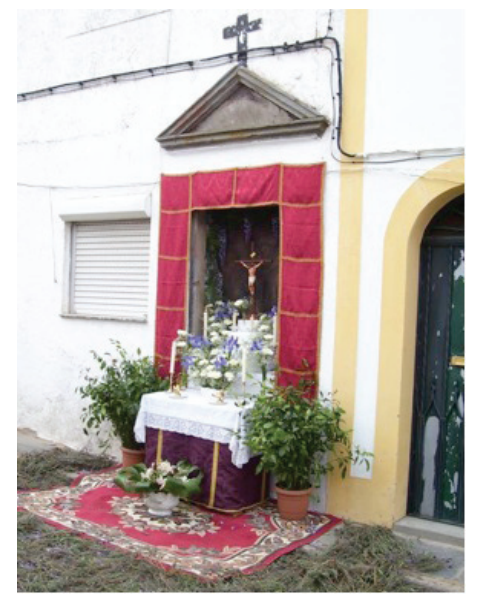

Fig.9. Estação dos Passos da Paixão do Senhor. Rua Joaquim José Vasconcelos Gusmão, Mourão (ca. 1690-1700). Aspecto geral, com arranjo para as festividades da Páscoa

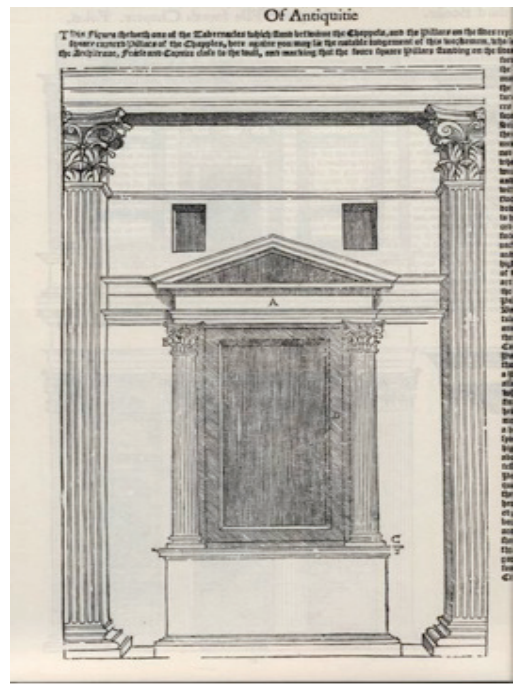

Fig.10. Sebastiano Serlio (1537). Modelo de altar coríntio, in The Five Books of Architecture. Nova Iorque, Ed. Robert Peake [1611] (1982, edição facsimile), 3, 4, fl. 16 


\section{Bibliografia}

1. Fontes tratadísticas

Sebastiano Serlio (1982) The Five Books of Architecture. Nova Iorque Ed. Robert Peake [1611] (edição facsimile).

Vitrúvio (2006), Tratado de Arquitectura. Ed e trad. M. Justino Maciel. Lisboa

2. Referências teórico-críticas

Leonardo Benevolo e Brenno Albrecht (2003), As Origens da Arquitectura. Lisboa. Françoise Choay (2007), A Regra e o Modelo. Casal de Cambra.

John Summerson (1994), A Linguagem Clássica da Arquitectura. S. Paulo.

3. Referências monográficas

J. E. Horta Correia (1991), Arquitectura Portuguesa. Lisboa.

J. E. Horta Correia (2002), “A importância da arquitectura de programa na História do Urbanismo português", in Actas do V Congresso Luso-Brasileiro de História da Arte. Faro 161-170.

Túlio Espanca (1966), Inventário Artístico de Portugal. Concelho de Évora. Lisboa.

Paulo Varela Gomes (2002), "Ordem abreviada e moldura de faixas, Contribuição para a discussão do conceito de 'Estilo Chão"', in Actas do V Congresso LusoBrasileiro de História da Arte. Faro. 